\title{
Ironia e crítica na poesia de Quintana
}

\author{
Maria da Glória Bordini \\ Pontifícia Universidade Católica do Rio Grande do Sul
}

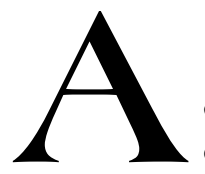

lírica tem sido definida como expressão de estados de alma, confundidos com efusões do sentimento. Entretanto, a questão da expressividade subjetiva em poesia é tão vasta e mutável historicamente, que não apenas emoções, mas reflexividade, crítica, denúncia e humor também são matéria para o lirismo. O que não pode nele faltar é a poeticidade, a capacidade de acentuar a materialidade da linguagem, o seu sistema fônico, a sua lógica, os elementos morfológicos e sintáticos, e as suas virtualidades semânticas, de modo a que venha a, como diz Heidegger, instaurar o Ser com a palavra. ${ }^{1}$

Mario Quintana, poeta de Alegrete, RS, nascido em 1906, atende a todos esses requisitos. Sua poesia tem a marca registrada dos grandes líricos, uma forte subjetividade que se manifesta em formas muito variadas, fixas e livres, aliando pensamento, paixão e uma bem-humorada ironia. Além disso, mantém uma firme pessoalidade, característica que já Manuel Bandeira lhe reconhecia em sua Apresentação da Poesia Brasileira, ${ }^{2}$ assim como uma feição moderna, atenta às sutilezas de seu tempo, como percebe o crítico Fausto Cunha. ${ }^{3}$

Essas qualidades, entretanto, não surgem por artes mágicas. Quando Mario Quintana começou a publicar, já era um apurado leitor de poesia e de narrativas, legado que lhe viera da infância. Desde criança, sua mãe lhe recitava poemas em espanhol dos românticos Bécquer e Espronceda e seu pai lia-lhe o Canto V dos Lusíadas de Camões. Não admira que, adulto, Quintana lembrasse a infeliz história de amor do titã Adamastor por Tétis, a filha do Oceano, em tantos poemas de amores impossíveis.

\footnotetext{
${ }^{1}$ HEIDEGGER, 1985, p. 137.

${ }^{2}$ BANDEIRA, 1946.

${ }^{3}$ CUNHA, 1978.
} 
Na sua juventude, Quintana foi um espírito inconformado. Acima de tudo poeta, tentou diversos ofícios, sem êxito. Foi prático na farmácia de seu pai, alistou-se como soldado na Revolução de 30, foi jornalista em Alegrete e em Porto Alegre, empregou-se como tradutor na Globo, mas suas inclinações pendiam de tal modo para a poesia que em nenhuma dessas atividades, nas quais se esmerou, segundo os que o conheceram, ele conseguiu encontrar-se.

Inadaptado ao mundo das conveniências e hipocrisias, Mario Quintana tornou-se um boêmio, vivendo em pensões e hotéis, entregue à ronda noturna dos bares com seus amigos do chamado Grupo da Globo dos anos 30, de que participavam, além de Augusto Meyer, Paulo Correa Lopes, Reynaldo Moura, Athos Damasceno Ferreira e Erico Verissimo, entre outros. Nessa época, ele, conselheiro editorial e tradutor de Proust para os Bertaso, deliciava-se com a leitura de parnasianos como Heredia e simbolistas como Verlaine e Mallarmé, poetas malditos como Baudelaire e Rimbaud e vanguardistas como Apollinaire.

Quintana admirava, assim como seus companheiros de grupo, os modernistas de São Paulo: liam e comentavam a Paulicéia Desvairada, de Mario de Andrade, o Pau Brasil, de Oswald de Andrade, os Borrões de Verde e Amarelo, de Cassiano Ricardo, mas impressionava-os acima de todos o Manuel Bandeira de Ritmo Dissoluto. Entretanto, por espírito de contradição, um dos seus traços mais característicos, o poeta de Alegrete dizia-se um clássico e lançou seus cinco primeiros livros adotando formas parnasianas como nos sonetos de A Rua dos Cataventos, ou provençais, como em Canções. Logo, porém, incidiu na moderna poesia em prosa de Sapato Florido, no verso livre e freqüentemente hermético de O Aprendiz de Feiticeiro e nos epigramas sarcásticos sob forma de quadras de Espelho Mágico. Tudo não passava de um jogo de ilusões, pois Quintana compusera todos esses livros ao mesmo tempo - alguns ele publicara na revista alegretense Ibirapuitã - e só por diversão separara os textos por formas clássicas e modernas, a brincar com as expectativas da época.

$\mathrm{Na}$ verdade, a forma unificadora, que conferia unidade a cada um desses primeiros livros, não passava de um malabarismo do poeta que já amadurecera, para veicular uma poesia que fixara sua voz própria e não se importava com os modismos literários. Quintana estava mais interessado em reagir à vida moderna, às agruras da cidade grande, à solidão, às vaidades humanas, fosse em tom apaixonado, enigmático ou sardônico. 
O "Soneto XXX" (de A Rua dos Cataventos, 1940), resume o jogo de ilusões que ele propõe a seus leitores nos anos 40. Inicia com ecos do tédio baudelairiano, a idéia de uma vida infinita e imemorial, passa a um trocadilho que ironiza o sofrimento típico dos líricos provençais, o penar, provoca os Doutores da Igreja, dispensando-os para obter a graça, e finaliza com um personagem citado de Dostoievski, o Idiota, desfazendo a sabedoria antes proclamada:

Rechinam meus sapatos rua em fora.

Tão leve estou que já nem sombra tenho

E há tantos anos de tão longe venho

Que nem me lembro de mais nada agora!

Tinha um surrão todo de penas cheio...

Um peso enorme para carregar!

Porém as penas, quando o vento veio,

Penas que eram... esvoaçaram no ar...

Todo de Deus me iluminei então.

Que os Doutores Sutis se escandalizem:

"Como é possível sem doutrinação?!"

Mas entendem-me o Céu e as criancinhas.

$\mathrm{E}$ ao ver-me assim, num poste as andorinhas

"Olha! É o Idiota desta Aldeia!: dizem...

Observando-se não apenas a seqüência de idéias do texto, mas seu tom, constata-se que a forma fixa do soneto - dois quartetos e dois tercetos, o último como chave de ouro, em decassílabos, observados à risca como entre os parnasianos e simbolistas - é subvertida pelas falas coloquiais inseridas dentro dos versos, pelas imagens auto-ironizantes, em especial pela metonímia inicial dos sapatos felizes pelo homem que se idiotiza para iluminar-se.

A ironia, em Quintana, não atua como a socrática, destinada a convencer, pela interrogação, o sofista de seus erros argumentativos, e nem sempre segue o modelo clássico de Quintiliano, de enganar o interlocutor ou subentender algo diferente do que se diz, para zombar ou atacar. As qualidades controversas e auto-irônicas do poema citado aproximam-se mais da posição romântica, como apresentada na obra $A$ ironia em Mario Quintana: 
o Romantismo adota uma posição dialética indicadora de capacidade reflexiva da ironia que, explorando um modo de ser simultaneamente sério e depreciativo a respeito de um assunto, torna tudo relativo e possibilita a coexistência do belo de do cômico, do sublime e do ridículo. ${ }^{4}$

Também a "Canção de Nuvem e Vento" (de Canções, 1946), sem renúncia à musicalidade e ao ritmo cadenciado do gênero, enquadra-se nessa posição romântica. Contradiz os temas da cantiga tradicional, ao propor uma reflexão sobre o desvanecimento das coisas sob a forma repetitiva das parlendas infantis:

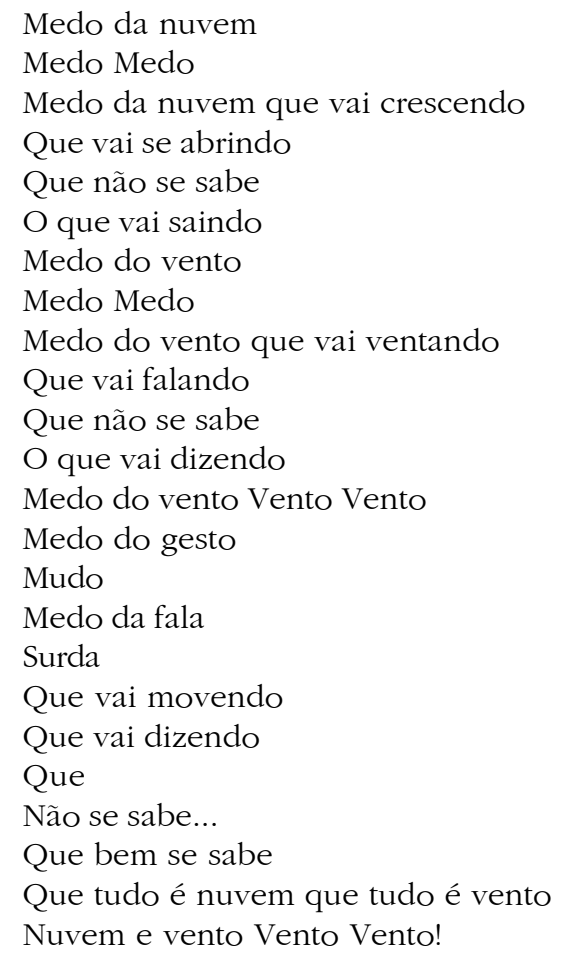

O refrão insistente, "medo medo", repetido anaforicamente, bem como o "e" fechado e nasalisado, que ressurge em "medo", "vento" e "nuvem", acompanhado pelas sibilâncias dos "ss" e os "vv" e "ff" fricativos, mais o

\footnotetext{
4 CLEMENTE; MOREIRA; CAMINHA, 1983, p. 25.
} 
golpear dos "tt" lábio-dentais mimetizam a sensação que o sujeito lírico quer materializar gradativamente para seu interlocutor, qual seja o temor ante a idéia de que tudo é vento e nuvem, nada permanece, noção ao mesmo tempo própria da modernidade, mas que remonta ao Livro da Sabedoria.

Aqui Quintana realiza um jogo irônico muito sutil, pois emprega a forma lúdica da parlenda para tratar de um tema adulto e sério, reduzindo o leitor a um estado de espírito infantil, como se o assunto não pudesse ser tratado senão com a ligeireza da canção para ser tolerado por homens crescidos.

Em Sapato Florido (1947), a tonalidade irônica se reveste de ludismo, embora o sentido subjacente seja de catástrofe da espécie humana. Veja-se que Quintana usa a imagem do Apocalipse de São João para liberar alguns entes não humanos do peso da humanidade, que assim é vista como prejudicial: os livros, o Pão de Açúcar, o hipopótamo, que se livram de nomes arbitrários, e Nosso Senhor, que é poupado da campanha por sua inexistência dos comunistas, de um lado, e pelo louvor excessivo de Athayde, de outro. Num texto assim breve, Quintana mobiliza, no subtexto irônico, idéias filosoficamente importantes como a nomeação e zomba bilateralmente de opostos como o comunismo x o catolicismo dos anos 40 .

\section{Apocalipse}

E eis que veio uma peste e acabou com todos os homens Mas em compensação ficaram as bibliotecas.

E nelas estava escrito o nome de todas as coisas.

Mas as coisas podiam chamar-se agora como bem quisessem.

E então o Pão de Açúcar se declarou Mancenilha.

E o hipopótamo só atendia por tico-tico.

E houve por tudo um grande espreguiçamento de alívio.

E Nosso Senhor ficou para sempre livre da terrível campanha dos comunistas.

E das apologéticas de Tristão de Athayde.

Em "Ao longo das janelas mortas" (de O Aprendiz de Feiticeiro, 1950), em verso livre e livre associação de imagens, desata-se num arroubo cheio de exclamações a indignação do sujeito lírico, um sonhador, ante o mundo de artifício que é o da modernidade: a vida automática, o passo compassado, as janelas fechadas, hostis, as estrelas de conta, a lua de papelão. O eu-lírico não poupa de invectivas sequer a si mesmo, numa auto-ironia sobre a inutilidade do poema que está escrevendo. A própria justaposição de cenas desconexas indicia o quanto Quintana estava 
afinado com o modernismo, com sua fragmentação do real, seu desencanto e as ligações alógicas dos versos, o que é complementado por um coloquialismo e enumeração caótica típicos do movimento:

Ao longo das janelas mortas

Ao longo das janelas mortas

Meu passo bate as calçadas.

Que estranho bate!... Será

Que a minha perna é de pau?

Ah, que esta vida é automática!

Estou exausto da gravitação dos astros!

Vou dar um tiro neste poema horrível!

Vou apitar chamando os guardas, os anjos, Nosso Senhor, as prostitutas, os mortos!

Venham ver minha degradação,

A minha sede insaciável de não sei o que,

As minhas rugas.

Tombai, estrelas de conta,

Lua falsa de papelão,

Manto bordado do céu!

Tombai, cobri com a santa inutilidade vossa.

Esta carcaça miserável de sonho...

Espelho Mágico (1951) põe à solta o espírito sardônico do poeta, através de epigramas carregados de malícia irônica, como o que segue. Nele se exemplifica claramente o mecanismo da sátira e sua relação com a ironia, a qual, segundo Linda Hutcheon, ${ }^{5}$ se dá pelo fato de que a primeira, num plano macro-textual, quer o escarmento dos defeitos humanos, enquanto a segunda atua invertendo sentidos aparentes e

\footnotetext{
${ }^{5}$ HUTCHEON, 1981. A teórica salienta a dupla especificidade da ironia, em seus aspectos semântico e pragmático. Diferencia ironia de paródia, que é questão de intertextualidade e se aplica a um texto ou convenções literárias, para transgredi-las. Também estabelece uma diferenciação entre ironia e sátira, lembrando que esta quer corrigir defeitos da humanidade. Para ela, a ironia funciona semanticamente superpondo dois enunciados, portanto, a nível micro-textual, e não em nível macro-textual, como a paródia. Pragmaticamente, se realiza às expensas de alguém, daí o uso que a sátira dela faz. O leitor tem de ter competência lingüística, genérica e ideológica para captar a ironia, mas a seu turno o autor tem de saber manipular o texto ao codificá-lo para obter o efeito irônico.
} 
subjacentes em nível micro-textual em afirmativas zombeteiras como "E nunca vês a tua":

\section{Da sátira}

A sátira é um espelho; em sua face nua,

Fielmente refletidas,

Descobres, de uma em uma, as caras conhecidas,

E nunca vês a tua...

Esses primeiros livros foram reunidos, em edição Globo, no volume Poesias (1962), depois chamado de Quintanares (1976). De certo modo, ilustram a arte poética do autor, que se desenvolveria nos textos dos anos 1970 no Caderno H(1973), em Apontamentos de História Sobrenatural (1976), em A Vaca e o Hipogrifo (1977). Nessas obras, o poeta olha compassivamente a tolice humana, diverte-se com as crises da História contemporânea, e provoca o leitor com versos enigmáticos de um lirismo profundamente dolorido, tanto quanto com cenas humorísticas e freqüentemente satíricas do cotidiano das grandes cidades. Veja-se, por exemplo, o poema abaixo retirado de Caderno $H$ :

\section{O citadino}

À primeira esquina, encontro uma cara oca, uma cara sem cara... O melhor, o melhor é voltar, o quanto antes, para o quarto. Com o máximo cuidado de não olhar, acaso, para o espelho.

Quintana, ao mesmo tempo que menciona os homens ocos, frutos inermes da uniformização da sociedade de massa, denunciados por T.S. Eliot em The Hollow Men, auto-ironiza-se, incluindo-se entre eles como possibilidade, o que revela uma capacidade de compreensão de si que o faz justamente o contrário deles, eximindo-se da vacuidade que percebe em torno. Como advertem os autores de A ironia em Mario Quintana,

O discurso irônico de Mario Quintana, com delicadeza, sutileza e humor, cumpre as funções da crítica social e de formação da visão de mundo, propondo um diálogo com o leitor, motivando-o a repensar a realidade e os valores que dela emanam, num jogo que promove o conhecimento de nós mesmos e do mundo que nos cerca, embora se perceba cada vez mais o acento grave de tristeza e desilusão. ${ }^{6}$

${ }^{6}$ CLEMENTE; MOREIRA; CAMINHA, p. 85. 
Em Apontamentos de História Sobrenatural a poesia sobe ao pódio das artes. O livro todo é atravessado pela potência transfiguradora do poético, mesmo ante as coisas mais triviais. Quintana, nessa obra, defende a transcendentalidade do poema em relação às outras manifestações expressivas do gênero humano. Observe-se a confiança no poder emancipatório da poesia e a ironia àqueles que dela fazem uso para desfigurá-la em espetáculos públicos:

"A beleza dos versos impressos em livro"

A beleza dos versos impressos em livro - serena beleza com algo de eternidade Antes que venha conturbá-los a voz das declamadoras. Ali repousam eles, misteriosos cântaros, Nas suas frágeis prateleiras de vidro... Ali repousam eles, imóveis e silenciosos. Mas não mudos e iguais como esses mortos em suas tumbas. Têm, cada um, um timbre diverso de silêncio...

Só tua alma distingue seus diferentes passos, Quando o único rumor em teu quarto É quando voltas, de alma suspensa - mais uma página Do livro... Mas um verso fere o teu peito como a espada de um anjo

E ficas, como se tivesses feito, sem querer, um milagre... Oh! que revoada, que revoada de asas!

Versos irônicos e até agressivos como "antes que venha conturbálos a voz das declamadoras" ou "Mas não mudos e iguais como esses mortos em suas tumbas" são empregados para realce da pureza do poema em si, que deve ser fruído "de alma suspensa". A ironia serve aqui de pano de fundo à tese do valor transcendente do texto poético, que fica salientado por contraste com o mundo em que não há anjos, nem milagres, mas só o exagero das "declamadoras".

O senso irônico de Quintana, ao longo de sua carreira, torna-se mais percuciente diante dos aspectos risíveis da sociedade contemporânea e transparece em sua lírica por estratégias eminentemente pragmáticas. Para alcançar a manifestação de seu desacerto com o mundo ele perturba a lógica da frase, da estrofação ou dos parágrafos tradicionais, criando efeitos de suspensão com a pontuação e as maiúsculas, quando não recorre à inserção de comentários, valendo-se com freqüência da metalinguagem, do monólogo e do apelo direto ao leitor. 
Algumas dessas características, tais como o uso do sinal de interrogação, o desequilíbrio da formação do soneto, a escolha deliberada de uma palavra como "bodoque", a criação de outra como o verbo "luarizar", podem ser encontradas em outro poema de Apontamentos, que transforma o tema usual dos noturnos, a "encantação lunar", numa crítica à tecnologia e aos cientistas que levam o homem à lua, mas não conseguem reproduzir o poder poético da natureza entregue a si mesma.

Num processo de amplificação hiperbólica, sobre a paisagem banhada pelo luar, cai a imobilidade: as janelas se apagam, as ruas ficam desertas. Sinestesicamente, no luar prateado, ouve-se apenas o cão que ladra, "mais humano que todas as máquinas", estabelecendo-se um contraste entre a máquina, cuja artificialidade é transferida ao gênero humano, que a produz, e o ladrido, som animal, que lembra a animalidade legítima do homem. Só o cão e um leitor cúmplice salvam o poeta de sentir-se "artificial com esta esferográfica" - note-se o efeito do dêitico, aproximando o ato de escrever o poema do leitor que o lê - o que o leva a abandonar o poema para render-se enfim ao feitiço da lua. Notese, no subtexto insinuado, que o efeito do luar impregna tudo apenas quando a cidade, signo da tecnologia humana, dorme.

\section{Lunar}

As casas cerraram seus milhares de pálpebras.

As ruas pouco a pouco deixaram de andar.

Só a lua multiplicou-se em todos os poços e poças.

Tudo está sob a encantação lunar...

E que importa se uns nossos artefatos

Lá conseguiram afinal chegar?

Fiquem armando os sábios seus bodoques:

A própria lua tem sua usina de luar...

E mesmo o cão que está ladrando agora

É mais humano do que todas as máquinas.

Sinto-me artificial com esta esferográfica.

Nem tanto... Alguém me há de ler com um meio sorriso

Cúmplice... Deixo pena e pape!... E, num feitiço antigo, à luz da lua inteiramente me luarizo...

Em A Vaca e o Hipogrifo, retorna a prosa poética de Caderno $H$, com os mesmos procedimentos que a experiência jornalística do autor tornara seu 
meio de comunicação efetivo com o leitor comum: a linguagem coloquial, a surpresa das conexões inesperadas entre as coisas e a zombaria irônica ante os temas do cotidiano e da arte, o que aparece claramente em:

\section{Do estilo}

Se alguém acha que estás escrevendo muito bem, desconfia... $\mathrm{O}$ crime perfeito não deixa vestígios.

Na década de 80, a poesia de Quintana vai se refinando ainda mais, em Esconderijos do Tempo (1980), assombrado pela fugacidade da vida e pelo amor já mais sexualizado do que nos livros anteriores. Essas características retornam em Baú de Espantos (1986), em que o papel da memória e da fantasia como resistência a um mundo caído se acentuam. O poeta não poupa de crítica até o sentimento amoroso, peça de resistência tradicional do lirismo. Veja-se, do primeiro:

\section{Bilhete}

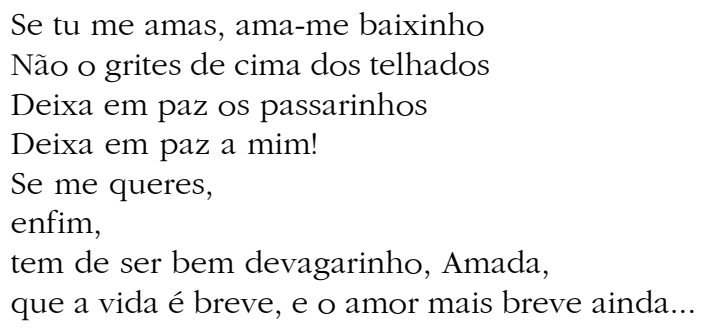

Neste texto, o amor romântico tem seu sinal invertido: deixa de ser paixão sem saída, que não alcança jamais a amada, para tornar-se discreto, quase furtivo, como se o desejo pelo outro não tolerasse a gritaria hodierna, a ostensividade hoje tão cultivada. Amar "bem devagarinho" se coloca contra a velocidade dos tempos modernos, numa crítica às relações apressadas, no sentido de valorizar o momento amoroso ante a fugacidade dos sentimentos, algo que a modernidade vem salientando poeticamente. Notese que o poema dialoga com o "Soneto de Fidelidade" de Vinícius de Moraes, num sentido também invertido, pois, em vez da eternidade passageira dos afetos do amante, o poema afasta os arroubos da amada, por inoportunos, o que confere ao texto um sense of humour meio retorcido.

Também "O pobre poema" (de Baú de Espantos) assume função crítica e proclama a necessidade de destruir a poesia falhada, que não 
consegue expressar os descaminhos do mundo real. Embora o poeta lamente elegiacamente, em ritmos dolentes, marcados por interrogações, rimas e aliterações esparsas, seu fracasso, ele o atribui, com ampla dose de sutileza irônica, ao fato de que pertence a um outro mundo, aquele em que uma "ternura mansa" de criança inocente contempla o descalabro da História atual com "incompreensível gravidade":

\section{O pobre poema}

Eu escrevi um poema horrível!

É claro que ele queria dizer alguma coisa...

Mas o quê?

Estaria engasgado?

Nas suas meias palavras havia no entanto uma ternura mansa como a que se vê nos olhos de uma criança doente, uma precoce, incompreensível gravidade de que, sem ler os jornais, soubesse dos seqiiestros dos que morrem sem culpa dos que se desviam porque todos os caminhos estão tomados...

Poema, menininho condenado, bem se via que ele não era deste mundo nem para este mundo...

Tomado, então, de um ódio insensato, esse ódio que enlouquece os homens ante a insuportável verdade, dilacerei-o em mil pedaços. E respirei...

Também! Quem mandou ter ele nascido no mundo errado?

A criatividade do poeta, porém, não se esgota fácil. Alcança os anos 90 com Da Preguiça Como Método de Trabalho e Preparativos de Viagem (ambos de 1987), Porta Giratória (1988) e ganha novo ímpeto em A Cor do Invisível (1989) e em Velório sem Defunto (1990). Nessa que será a última fase da produção de Quintana o que se percebe é uma maior prosificação do poema, como se ele desejasse chegar bem perto do que é prosaico na vida, para resgatá-lo pelo poder da poesia. Há também um interesse mais detido nos eventos da história pública e privada, examinando-os sob uma lente sempre irônica, mas de cada vez mais forte magnificação crítica, como em: 


\section{Seleção artificial}

As guerras não ajudam muito a remediar o que se denomina (bombasticamente) de explosão demográfica: os que ficam em casa aproveitam a deixa para multiplicar-se: E como os que partem são agora escolhidos entre os mais aptos de físico e de espírito, imagine o pobre leitor o que não será isso para a evolução do Homo sapiens...

A vida na sociedade burguesa é esmiuçada com recursos irônicos sutis, indicando a posição ideológica do poeta, aquela que a crítica inicial de Quintana costumava qualificar de alienada, sem perceber que não cair no panfletarismo político pode ser mais efetivo em termos de conscientização. Com certeza não é alheamento o que se depreende de um poema como "História Burguesa", em que os hábitos da classe média das pequenas cidades interioranas são sarcasticamente figurados, para ao final serem iluminados por um flash de poeticidade, que os acentua ainda mais.

Era à 1uz dos 1ampiões de querosene

Que a gente fazia os deveres escolares.

Nas paredes, São Jorge e o seu cavalo branco

Nos sugeriam - que digo? - nos impunham mais graves deveres.

E ninguém notava.

Depois, a lâmpada elétrica e, nas paredes

O Marechal Deodoro a proclamar sempre e sempre a República

- e ninguém notava.

Enquanto isso, em todos os centros-de-mesa de todas as casas burguesas

Ostentava-se a grande moda das flores artificiais

- Todo mundo notava.

(O que é a natureza! - dizia dona Glorinha - até parecem verdadeiras!)

Até que um dia um papa decretou que São Jorge jamais havia existido.

Agora, apenas o seu cavalo branco ainda corre solto por aí.

(Mas ninguém, ninguém se atreve a montar num cavalo-fantasma).

Assim também ocorre com modismos da pós-modernidade, ironicamente representados em pequenas cenas de forte impacto visual, como em 


\section{Passarela}

Um desfile de manequins, neste nosso desidratado século, lembra-nos graciosas figuras feitas com paus de fósforos.

Em sua dissertação de mestrado, José Carlos de Freitas aponta a função de resistência da lírica de Quintana, vendo-a como afirmação ante o adverso, uma resistência como a dos que "sabendo que o mundo se pauta por mecanismos de expulsão, extorsão e esgotamento, têm uma teimosia, santa ou profana, de acreditar que um dia ele pode ser melhor". ${ }^{7}$ Percebe com sensibilidade "o sentido de desenraizamento e desfiguramento lamentado pelo poeta", 8 como o evidencia o poema abaixo, em que o poeta assume de modo inequívoco um lugar ao lado dos humildes e ofendidos que Dostoievski elevou em sua literatura:

\section{Dedicatória}

Quem foi que disse que eu escrevo para as elites?

Quem foi que disse que eu escrevo para o bas-fond?

Eu escrevo para a Maria de Todo o Dia.

Eu escrevo para o João Cara de Pão.

Para você, que está com este jornal na mão...

E de súbito descobre que a única novidade é a poesia,

O resto não passa de crônica policial - social - política.

E os jornais sempre proclamam que "a situação é critica"!

Mas eu escrevo é para o João e a Maria,

Que quase sempre estão em situação crítica!

E por isso as minhas palavras são quotidianas como o pão

[nosso de cada dia

E a minha poesia é natural e simples como a água bebida na concha da mão.

O fato de o poema chamar-se "Dedicatória" e aparecer numa obra do final da carreira do poeta ( $A$ cor do invisivel) reassegura seu compromisso modestamente assumido de denúncia de uma sociedade em que sempre "a situação é crítica", como a brasileira, em que os poderosos - extrato em que o poeta iguala a elite e os bandidos, dado o paralelismo dos versos - tecem as redes que mantêm o povo aprisionado na rotina aflita do dia-a-dia, sem nada a não ser notícias desalentadoras da mídia.

\footnotetext{
7 FREITAS, 2005, p.11.

${ }^{8}$ FREITAS, 2005, p. 12.
} 
Regina Zilberman, no ensaio "Diversidade sempre fiel a si mesma"" afirma que o poeta está muito além do "individualista empedernido" que certa crítica viu nele. Lembra que Quintana, apesar de dizer "nada entendo da questão social", não se põe à margem dela, opondo-se multiformemente ao progresso que descaracteriza o meio e ao capitalismo que explora o homem. Isso também o crítico Santiago Kovadloff constata em "Mario Quintana: trayectoria de uma voz", referindo que o poeta questiona "um conceito de desenvolvimento que desatende o lado sentimental da experiência, as necessidades afetivas do homem e, em última instância, a compreensão radical da existência intimamente associada à do tempo". ${ }^{10}$

Daí o papel exponencial de que a poesia é investida em toda a obra de Quintana. Sua arma, no bom combate, não deriva da mídia, das redes eletrônicas, da super-exposição pessoal. É no recolhimento do eu, no cultivo de uma intensidade lírica só atingida na solidão, numa solidão que não se aliena, mas se distancia para poder olhar, que Quintana exerce sua crítica irônica dos dias que correm e dá substância a uma produção que permanece como diagnóstico e como denúncia.

Uma vida devotada ao poético como a dele só poderia encerrar-se em versos que reafirmam a potência do poema como objeto de resistência às configurações adversas do mundo contemporâneo. Note-se a fragmentação do continuum, a enumeração caótica, toda uma infinitude desgarrada, enfeixada nos versos finais, que celebram a poesia, como ele o fez a vida inteira:

\section{O tamanho do espaço}

A medida do espaço somos nós, homens, Baterias de cozinha e jazz-band, Estrelas, pássaros, satélites perdidos, Aquele cabide no recinto do meu quarto, Com toda a minha preguiça dependurada nele... O espaço, que seria dele sem nós?

Mas o que enche, mesmo, toda a sua infinitude

É o poema!

- por mais leve, mais breve, por mínimo que seja...

\footnotetext{
9 ZILBERMAN, 1982.

${ }^{10}$ KOVADLOFF, s. d.
} 


\section{Referências Bibliográficas}

HEIDEGGER, Martin. Hölderlin y la esencia de la poesía. In: Arte y poesía. México: Fondo de Cultura Económica, 1985.

BANDEIRA, Manuel. Apresentação da poesia brasileira. Rio de Janeiro: Casa do Estudante do Brasil, 1946.

CUNHA, Fausto. Poesia e poética de Mario Quintana. In: A leitura aberta: estudos de crítica literária. Rio de Janeiro: Cátedra; Instituto Nacional do Livro, 1978. CLEMENTE, Ir. Elvo; MOREIRA, Alice Therezinha Campos; CAMINHA, Heda Maciel. A ironia em Mario Quitana. Porto Alegre: Acadêmica, 1983.

HUTCHEON, Linda. Ironie, satire, parodie: une approche pragmatique de l'ironie. Poétique, Paris: Seuil, v. 46, p. 140-155, 1981.

FREITAS, José Carlos de. Os dançarinos do arame: lirismo e resistência em Mario Quintana. 2005. Dissertação (Mestrado em Letras/Literatura Brasileira e Teorias da Literatura) - Universidade Federal Fluminense.

ZILBERMAN, Regina. Mario Quintana. São Paulo: Abril Cultural, 1982. (Literatura Comentada).

KOVADLOFF, Santiago. Mario Quintana: trayectoria de uma voz. Cuadernos Hispanoamericanos, Madrid, n. 462, p. 97.

\section{Resumo}

A poesia de Mario Quintana já foi acusada de alienação e sentimentalidade. O exame das figuras e cenas de duplo sentido, efetuado ao longo de sua obra, desde A Rua dos Cataventos até Velório sem Defunto, desmente a crítica e revela um apurado senso de denúncia das condições da vida moderna, com emprego consistente de estratégias irônicas, sem renúncia à intensidade emocional característica do lirismo.

\section{Résumé}

Cette étude démente une critique qui voit dans la poésie de Mário Quintana l'aliénation du poète et un excès de sentimentalisme. 